\title{
DESIGN OF DUAL BAND DISSIMILAR PATCH SIZE ARRAY ANTENNA FOR WIRELESS APPLICATIONS
}

\author{
R.Rajeswari ${ }^{1,}$ P.Sudharshini ${ }^{2}$, S.V.Vidhya harini ${ }^{3}$ \\ ${ }^{1}$ Assistant Professor, Dept. of ECE, VCET, Madurai \\ ${ }^{2-3}$ UG Student, Dept. of ECE, VCET, Madurai
}

\begin{abstract}
-
This paper deals with the design of a dual band array antenna for wireless applications such as LTE (Long Term Evolution), WiMAX etc...that resonates at $3.5 \mathrm{GHz}$ and $5 \mathrm{GHz}$ respectively. The substrate used for design is FR4 $\left(\epsilon_{r}=4.6\right)$ and the software used for simulation is Agilent ADS Momentum. The concept of dissimilar patch size array antenna has been introduced. So patches of different dimensions have been used in the array and their corresponding results are validated based on various antenna parameters like VSWR, gain, directivity and power radiated.
\end{abstract}

\section{Keywords-}

Patch antenna; dual-band; LTE; WiMAX; MIMO

\section{INTRODUCTION}

The rapid growth of wireless communication systems has increased the demand for compact antennas with multiband operating frequencies. In some cases, the bandwidth of the entire frequency range could be covered with the antenna. Owing to their low-profile, low-cost, and low-mass features, microstrip antennas can be easily placed inside packages, making them a suitable choice for numerous consumer applications. There is huge demand for new kind of antennas such as small antennas, multifrequency antennas, broadband antennas for mobile and satellite communication systems. A dual band antenna is an antenna designed for use on two different bands which provides various applications such as Wireless Communications, satellite communications, Area monitoring, Forest fire detection, Disaster prevention. A patch antenna (also known as a rectangular Microstrip antenna) is a type of radio antenna with a low profile, which can be mounted on a flat surface. It consists of a flat rectangular sheet or "patch" of metal, mounted over a larger sheet of metal called a ground plane.

Planar antennas [1] are preferred because of their small size and simple structure. One of the main types of planar antennas is microstrip patch antenna. They are preferred over other planar antennas because of their thin profile. A patch antenna is a piece of metal mounted on a substrate of thickness $h$ and dielectric constant $\epsilon_{r}$. It is an easy to fabricate, low cost, small-sized and low weight antenna [1].These properties of microstrip patch antennas make them most suitable for mobile devices. A simple rectangular patch antenna typically resonates at a single resonance frequency $\mathrm{F}_{\mathrm{r}}$ [2]. Multiple Input Multiple Output (MIMO) is considered as a key smart antenna technology, to improve the capacity of a communication channel at a greater extent [3], because it makes it possible to transmit multiple data streams over a same frequency channel without increasing the physical bandwidth of that channel [4].MIMO utilizes multiple antenna elements both at transmitter and receiver ends to increase the data transmission rate by providing higher spectral efficiency [3].The 4G cellular mobile communication standards, Long Term Evolution(LTE) and WiMAX[4], utilizes MIMO to provide improved data rate of up to $1 \mathrm{Gbps}$

DOI : $10.5121 / \mathrm{ijist} .2014 .4305$ 


\section{ANTENNA DESIGN}

Our goal is to design a dual band microstrip patch antenna array at $3.5 \mathrm{GHz}$ and $5.0 \mathrm{GHz}$ using ADS simulation software. We used microstrip line (edge feed) technique to feed the microstrip patch antenna covering both the frequencies.

\section{A. Two element antenna design}

Substrate selection is the first practical step in designing a patch antenna. FR4 $\left(\epsilon_{r}=4.6\right)$ is used as substrate to design the patch antenna. These values are carefully chosen to meet our performance and bandwidth requirement because dielectric material is crucial for determining the performance of antenna. To achieve compactness, thin substrates are required but the bandwidth of antenna decreases as height is reduced. Also with higher values of $\epsilon_{r}$ the patch size can be reduced but it would also reduce the antenna bandwidth. So, a trade-off must be done between antenna performance and its size $[1,5]$. The empirical formulas in [6] are used here to obtain the initial parameters of dual band patch antenna. The dimensions for different patch size are calculated. The length of the large patch radiator is $22.2 \mathrm{~mm}$ and width is $28.1 \mathrm{~mm}$ whereas the length of the small patch radiator is $14.565 \mathrm{~mm}$ and width is $19.7 \mathrm{~mm}$. Length of the feedline is $12 \mathrm{~mm}$ and width is $0.7 \mathrm{~mm}$. Distance between the centers of both the feedline is $59.3 \mathrm{~mm}$. (fig.1)

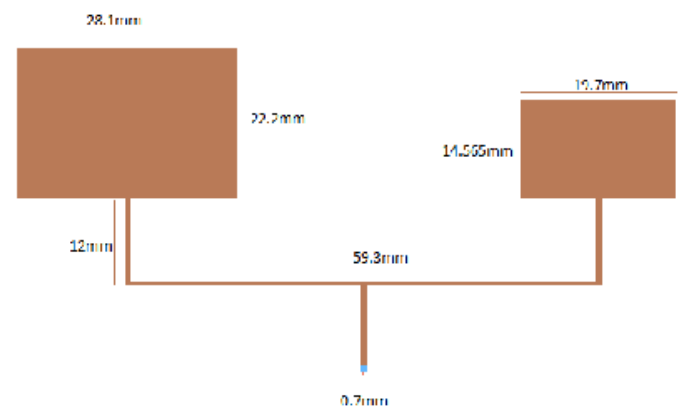

Figure 1(a) : Array of 2 elements with ideal ground plane covering both the frequencies of $3.5 \mathrm{GHz}$ and $5.0 \mathrm{GHz}$.

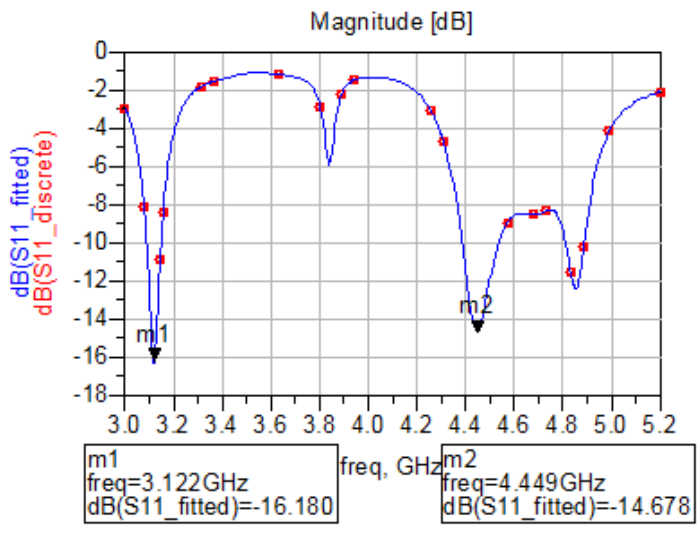

Figure 1(b): Radiation pattern of two element array antenna. 


\section{B.Four element antenna design}

The length of the large patch radiator is $21.7 \mathrm{~mm}$ and width is $28.1 \mathrm{~mm}$ whereas the length of the small patch radiator is $14.84 \mathrm{~mm}$ and width is $19.7 \mathrm{~mm}$. Length of the feedline is $12 \mathrm{~mm}$ and width is $0.7 \mathrm{~mm}$. Distance between the centre of both the 2 element feedline is $59.3 \mathrm{~mm}$. Distance between the edges of above and below radiator is $61.4 \mathrm{~mm}$. The efficiency of the antenna is found to be $70.096 \%$.

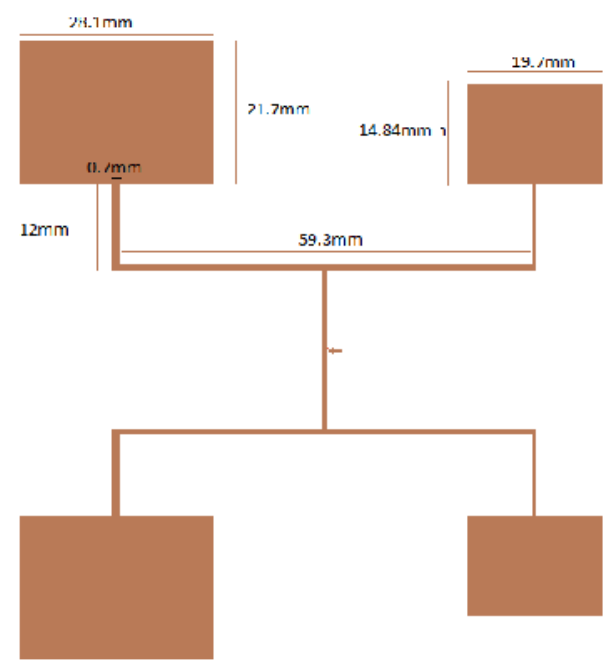

Figure 2(a): Array of 4 elements with ideal ground plane covering both the frequencies of $3.5 \mathrm{GHz}$ and 5.0 $\mathrm{GHz}$.

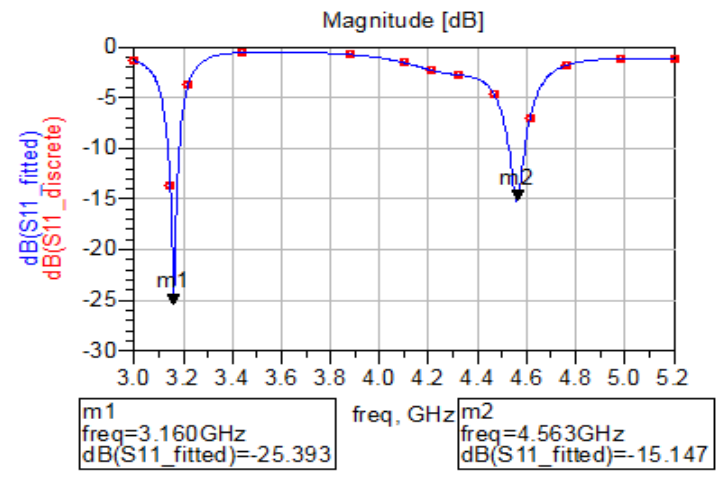

Figure: 2(b)

Figure 2(b): Radiation pattern for four element array antenna.

\section{C.Eight element antenna design}

The length of the large patch radiator is $21.3 \mathrm{~mm}$ and width is $28.1 \mathrm{~mm}$ whereas the length of the small patch radiator is $14.7 \mathrm{~mm}$ and width is $19.7 \mathrm{~mm}$. Length of the feedline is $12 \mathrm{~mm}$ and width is $0.7 \mathrm{~mm}$. Distance between the centre of both the 2 element feedline is $59.3 \mathrm{~mm}$. Distance between the edges of above and below radiator is $61.4 \mathrm{~mm}$. Distance between the centre of both the 4 element array feedline is $121.7 \mathrm{~mm}$. The efficiency of the antenna is found to be $73.05 \%$. 
International Journal of Information Sciences and Techniques (IJIST) Vol.4, No.3, May 2014

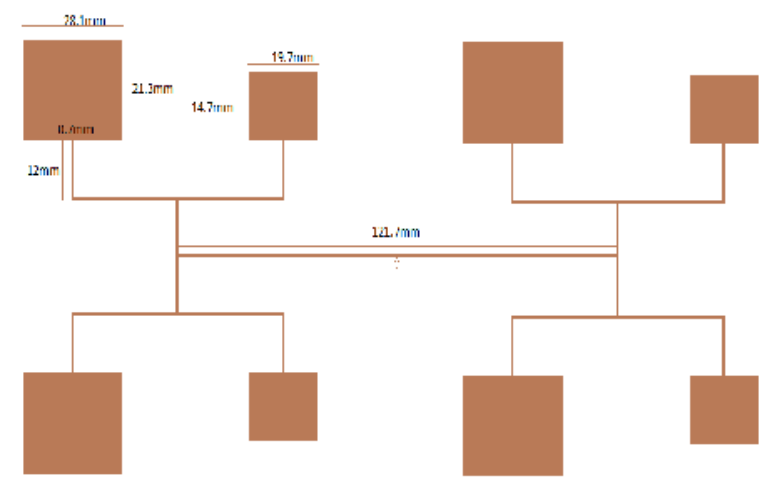

Figure 3(a): Array of 8 elements with ideal ground plane covering both the frequencies of $3.5 \mathrm{GHz}$ and 5.0 $\mathrm{GHz}$.

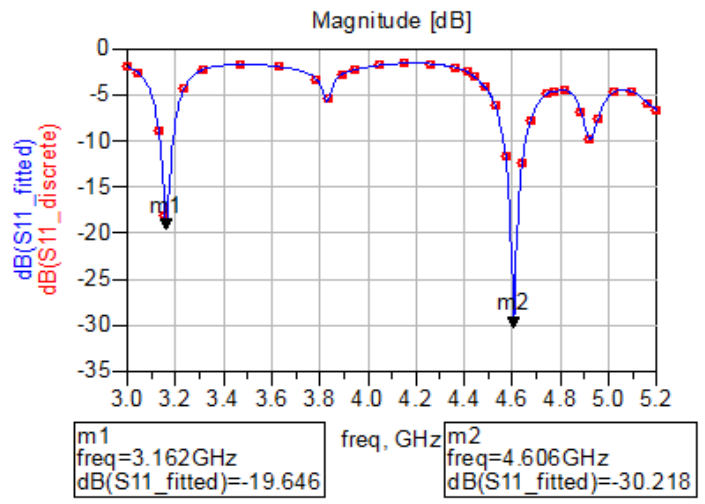

Figure: 3(b)

Figure 3(b): Radiation pattern of eight element array antenna.

\section{Sixteen element antenna design}

The length of the large patch radiator is $21.3 \mathrm{~mm}$ and width is $28.1 \mathrm{~mm}$ whereas the length of the small patch radiator is $14.7 \mathrm{~mm}$ and width is $19.7 \mathrm{~mm}$. Length of the feedline is $12 \mathrm{~mm}$ and width is $0.7 \mathrm{~mm}$. Distance between the centre of both the 2 element feedline is $59.3 \mathrm{~mm}$. Distance between the edges of above and below radiator in 4 element is $61.4 \mathrm{~mm}$. Distance between the centre of both the 4 element array feedline is $217.4 \mathrm{~mm}$. Distance between the centre of both the 8 element array feedline is $190 \mathrm{~mm}$. 
International Journal of Information Sciences and Techniques (IJIST) Vol.4, No.3, May 2014

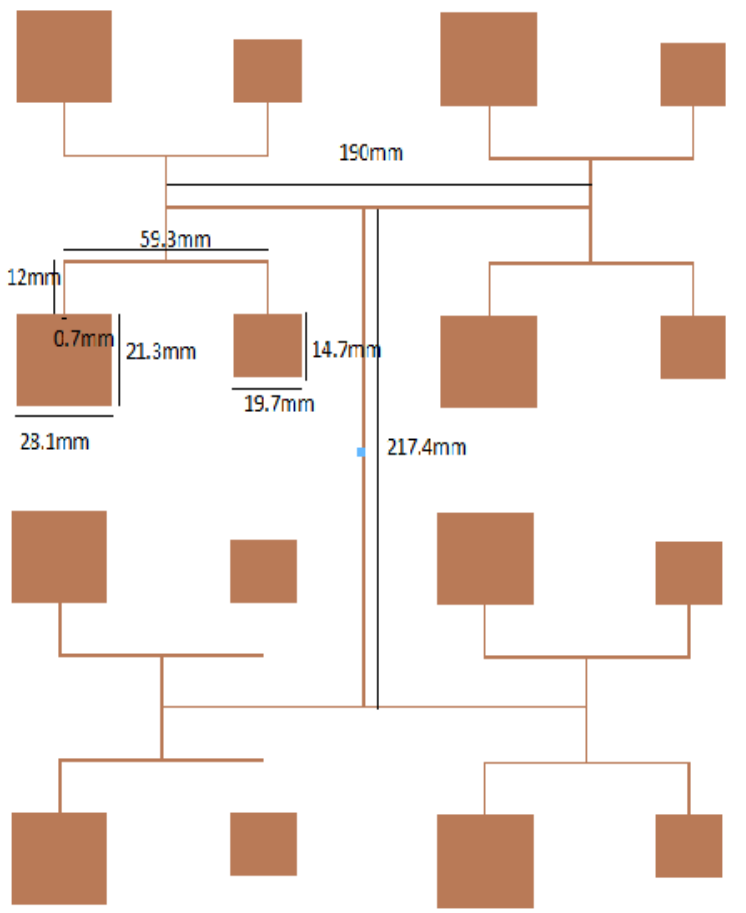

Figure 4(a): Array of 16 elements with ideal ground plane covering both the frequencies of $3.1 \mathrm{GHz}$ and $4.5 \mathrm{GHz}$.

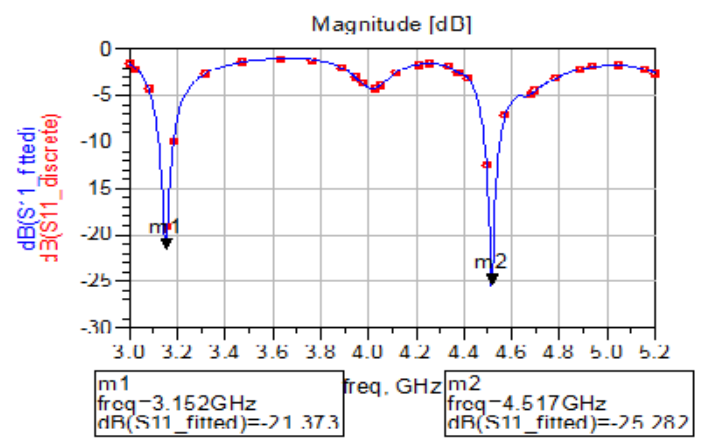

Figure 4(b): Plot of return loss vs. frequency of sixteen element array antenna.

\section{RESULTS AND DISCUSSIONS}

The return loss is determined for the two, four, eight element antenna respectively and a better return loss was observed in eight element antenna and the results are tabulated in table I. 


\begin{tabular}{|c|c|c|}
\hline $\begin{array}{c}\text { Array } \\
\text { element }\end{array}$ & $\begin{array}{c}\text { Freq } \\
(\mathrm{GHz})\end{array}$ & $\begin{array}{c}\text { Return loss,S(1,1), } \\
(\mathrm{dB})\end{array}$ \\
\hline \multirow{2}{*}{2} & 3.1 & -16.18 \\
\cline { 2 - 3 } & 4.5 & -14.67 \\
\hline \multirow{2}{*}{4} & 3.1 & -25.39 \\
\cline { 2 - 3 } & 4.5 & -15.14 \\
\hline \multirow{2}{*}{8} & 3.1 & -19.64 \\
\cline { 2 - 3 } & 4.5 & -30.21 \\
\hline \multirow{2}{*}{16} & 3.1 & -21.37 \\
\cline { 2 - 3 } & 4.5 & -25.28 \\
\hline
\end{tabular}

Table I: Comparison of return loss for different array element

The VSWR is determined for the two, four, eight element antenna respectively. The optimum VSWR is in the range of 1.6 and we have achieved it in our antenna design and the results are tabulated in table II.

\begin{tabular}{|c|c|c|}
\hline Array element & $\begin{array}{c}\text { Freq } \\
(\mathrm{GHz})\end{array}$ & VSWR \\
\hline \multirow{2}{*}{2} & 3.1 & 1.36 \\
\cline { 2 - 3 } & 4.5 & 1.46 \\
\hline \multirow{2}{*}{4} & 3.1 & 1.28 \\
\cline { 2 - 3 } & 4.5 & 1.52 \\
\hline \multirow{2}{*}{16} & 3.1 & 1.39 \\
\cline { 2 - 3 } & 4.5 & 1.32 \\
\hline \multirow{2}{*}{16} & 3.1 & 1.19 \\
\cline { 2 - 3 } & 4.5 & 1.11 \\
\hline
\end{tabular}

Table II: Comparison of VSWR for different array element

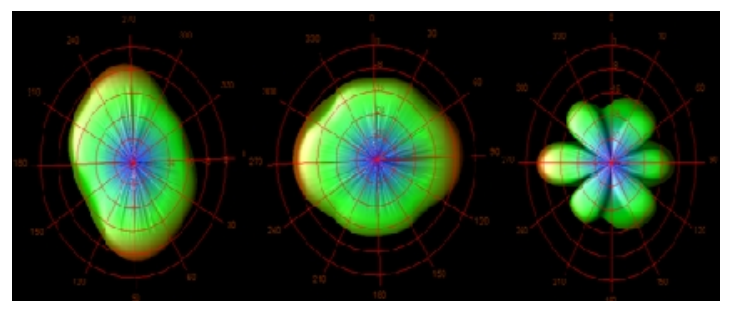

Figure 4: Comparative study of radiation pattern of two, four, eight element respectively

The gain is determined for the two, four, eight element antenna respectively and a better gain of $9.250 \mathrm{~dB}$ was observed in eight element antenna and the results are tabulated in table III

\begin{tabular}{|c|c|}
\hline Array element & Gain $(\mathrm{dB})$ \\
\hline 2 & 5.006 \\
\hline 4 & 6.91 \\
\hline 8 & 9.72 \\
\hline 16 & 9.95 \\
\hline
\end{tabular}


Table III: Comparison of Gain for different array element

The bandwidth is determined for the two, four, eight element antenna respectively. $F_{L}$ denotes lower frequency and $\mathrm{F}_{\mathrm{H}}$ denotes higher frequency and the bandwidth is obtained in the range of mega hertz and the corresponding the results are tabulated in table IV.

\begin{tabular}{|c|c|c|c|c|}
\hline $\begin{array}{c}\text { Antenna } \\
\text { array } \\
\text { elements }\end{array}$ & $\begin{array}{c}\text { Freq } \\
(\mathrm{GHz})\end{array}$ & $\begin{array}{c}\mathrm{F}_{\mathrm{L}} \\
(\mathrm{GHz})\end{array}$ & $\begin{array}{c}\mathrm{F}_{\mathrm{H}} \\
(\mathrm{GHz})\end{array}$ & $\begin{array}{c}\text { Bandwidth } \\
(\mathrm{MHz})\end{array}$ \\
\hline \multirow{2}{*}{2} & 3.1 & 3.10 & 3.15 & 50 \\
\cline { 2 - 5 } & 4.5 & 4.24 & 4.32 & 80 \\
\hline \multirow{2}{*}{8} & 3.1 & 3.12 & 3.19 & 70 \\
\cline { 2 - 5 } & 4.5 & 4.50 & 4.61 & 110 \\
\hline \multirow{2}{*}{16} & 3.1 & 3.12 & 3.21 & 90 \\
\cline { 2 - 5 } & 4.5 & 4.54 & 4.67 & 130 \\
\hline \multirow{2}{*}{16} & 3.1 & 3.10 & 3.20 & 100 \\
\cline { 2 - 5 } & 4.5 & 4.46 & 4.57 & 150 \\
\hline
\end{tabular}

Table IV: Comparison of bandwidth for different array element for two frequency $3.1 \mathrm{GHz}$ and $4.5 \mathrm{GHz}$

\section{CONCLUSION}

A dual-band microstrip patch antenna array for LTE, WiMAX and other wireless applications is presented. The antenna covers $3.1 \mathrm{GHz}$ and $4.5 \mathrm{GHz}$ frequency bands .Good results are obtained in terms of return loss, VSWR and array gain. The use of Agilent ADS software ensures that there would not be large differences between the results of simulated and measurements of fabricated antenna. The fabrication will be performed using the same FR4 substrate to compare antenna results.

\section{REFERENCES}

[1] Constantine A. Balanis, Antenna Theory, Analysis and Design, Third Edition, John Wiley \& Sons, Inc. 2005.

[2] Y. X. Guo, K. M. Luk, K. F. Lee and Y. L. Chow, "Double U-slot rectangular patch antenna," Electronics Letters, vol. 34, pp. IS05-IS06,Sept. 1995.

[3] G. J. Foschini, "Layered space-time architecture for wireless communication in a fading environment when using multi-element antennas," Bell Labs Technical Journal, pp 41-59, autumn 1996 [4]Martin Sauter, Beyond 3G - Bringing Networks, Terminals and the Web Together, John Wiley \& Sons Ltd,2009

[5] Garg, R. Bhartia, P., Bahl, I., Ittipiboon, A., Microstrip antenna design handbook, Artech House, Inc, 2001..

[6] Weigand, G. H. Huff, K. H. Pan, J. T. Bernhard, "Analysis and design of broad-band single layer rectangular U-slot microstrip patch antennas," IEEE Transactions on Antennas and Propagation, vol. 51, no. 3, March 2003.

\section{Authors}

Prof.R.Rajeswari, is working in Electronics and Communication Engineering Department at Velammal College of Engineering and Technology, Madurai, received her B.E degree (ECE) at K.L.N college of Information and Technology, Madurai , M.E degree (Communication systems) at Sri Venkateswara College of Engineering, Chennai. She has published several papers in National and International Conferences. Her areas

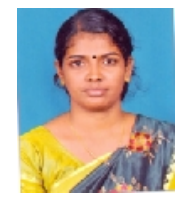


International Journal of Information Sciences and Techniques (IJIST) Vol.4, No.3, May 2014

of interest are microwaves, Electromagnetics and Antenna Design. She is a Life Member of Indian Society of Technical Education (ISTE).

P.Sudharshini was born on 03.04.1992. She pursues final year B.E in Velammal C ollege of Engineering and Technology, Madurai. Her research areas include Antenna design.

S.V.Vidhya Harini was born on 28.12.1992. She pursues final year B.E in Velammal College of Engineering and Technology, Madurai. Her research areas include Antenna design.
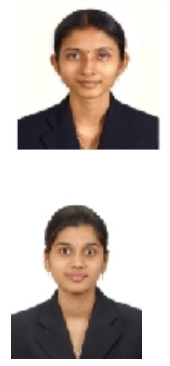